\title{
LAS PERPLEJIDADES ÉTICAS DEL REY LUDWIG II DE BAVIERA: LOCURA, EXTRAVAGANCIA Y PROFESIÓN MÉDICA
}

\author{
Gustavo Figueroa ${ }^{1}$
}

Resumen: 1. Bernhard von Gudden diagnosticó el trastorno del Rey Ludwig II de Baviera como "paranoia” (locura), aunque Ludwig nunca fue personalmente evaluado por este experto psiquiatra, diagnóstico que usó el gobierno bávaro para justificar la remoción de Ludwig del poder. 2. Su conducta progresivamente anormal; sus proyectos múltiples de construcción, por los cuales incurrió en fuertes deudas; su convicción de descender directamente de los Borbones gracias al "bautismo"; su desenfrenada vida homosexual, todo constituyó la base para el diagnóstico psiquiátrico. 3. De acuerdo con los criterios actuales de la psiquiatría, Ludwig mostró rasgos de un trastorno de personalidad esquizotípico, unido a un sindrome orbitofrontal, y un modo de existencia extravagante. 4. Bernhard von Gudden fundamentó su diagnóstico y peritaje psiquiátricos siguiendo los principios éticos de beneficencia y primum non nocere, "ayudar, al menos no dañar".

Palabras clave: profesionalidad, médico; gestión de la práctica, médico; paranoia; trastorno esquizotípico de la personalidad; principio de beneficencia.

\section{The ethical perplexities of king Ludwig II of Bavaria: madness, extravagance and medical profession}

\begin{abstract}
Bernhard von Guden diagnosed the Bavarian King Ludwig II with "paranoia" (madness), although Ludwig was not personally evaluated by this expert psychiatrist, a diagnosis that the Bavarian government used to justify removing Ludwig from power. 2. His increasingly abnormal behavior, his multiply building projects, for which he incurred much debt, his conviction that he descended from the Bourbons through "baptism", his unbridled homosexual life, together formed the basis for the psychiatrist's diagnosis. 3. According to modern criteria of psychiatry Ludwig displayed traits for schizotypal personality disorder together with an orbitofrontal syndrome, and an extravagance way of existence. 4.Bernhard von Gudden based his psychiatric diagnosis and expertise following the ethical principles of beneficence and primum non nocere, "to help, at least not to harm"
\end{abstract}

Key words: professionalism, medical; practice management, medical; paranoia; schizotypal personality disorder; principle of beneficence

\section{As perplexidades éticas do Rei Ludwig II da Baviera: loucura, extravagancia e profissáo médica}

Resumo: 1. Bernhard von Gudden diagnosticou o transtorno do Rei Ludwig II da Baviera como "paranoia” (loucura), ainda que Ludwig nunca tenha sido pessoalmente avaliado por este especialista psiquiatra, diagnóstico que o governo bávaro usou para justificar a remoçấo de Ludwig do poder. 2. Sua conduta progressivamente anormal; seus projetos múltiplos de construção, pelos quais incorreu em fortes dívidas; sua convicção de descender diretamente dos Bourbons graças ao "batismo"; sua desenfreada vida homossexual, tudo constituiu a base para o diagnóstico psiquiátrico. 3. De acordo com os critérios atuais da psiquiatria, Ludwig mostrou traços de um transtorno de personalidade esquizotípico, unido a uma síndrome órbito-frontal e um modo de existência extravagante. 4. Bernhard von Gudden fundamentou seu diagnóstico e perícia psiquiátrica seguindo os princípios éticos de beneficência e primum non nocere, "ajudar, ao menos não prejudicar".

Palavras chave: profissionalidade médica; gestão da prática médica; paranoia; transtorno esquizotípico da personalidade; principio de beneficência

\footnotetext{
${ }^{1}$ Departamento de Psiquiatría, Escuela de Medicina, Universidad de Valparaíso, Chile. Correspondencia: gfigueroacave@gmail.com
} 
Desde joven el rey Ludwig II de Baviera (18451886) gustaba de repetir las palabras de Beatriz de Schiller: "Quiero permanecer un eterno enigma para mí y para los otros"(1). El enigma en que consistió su existencia culminó en un perturbador y sobrecogedor final. El 10 de junio de 1886 una "Comisión Real" del más alto rango, presidida por el ministro del gobierno von Crailsheim y el presidente de la comisión médica doctor Bernhard von Gudden, se dirige al Castillo Neuschwanstein, donde reside, a comunicarle personalmente que se le ha destituido como monarca por padecer del trastorno mental irrecuperable de "paranoia" y, siguiendo órdenes de su sucesor, Príncipe Regente Luitpold, en conformidad con el gobierno, debe ser trasladado de inmediato al Castillo Berg en calidad de internado. Tras disputas, hostilidades, amenazas, es ingresado con custodia el 13 de junio en el recinto real colindante al lago Starnberg y, concluido un cordial almuerzo, él propone pasear por las márgenes acompañado del doctor von Gudden, muriendo ambos en circunstancias enigmáticas en la ribera del lago, después de tres horas de frenética búsqueda bajo intensa lluvia(2). Trascurrido cerca de siglo y medio las interrogantes persisten, a pesar de múltiples, sucesivas y rigurosas investigaciones, aunque plagadas de prejuicios, suspicacias, estudios que involucran personas, instituciones, regímenes(3). Adquiere mayor trascendencia actual, puesto que compromete los fundamentos e interrelación de los campos de la psiquiatría, jurisprudencia y política, además que a nuestra época se la entiende sustentada por el biopoder, ejercicio del poder condicionando la vida y muerte biológica y personal(4). Entre las acuciantes interrogantes que rodean al infausto destino del rey, el presente trabajo aborda dos ámbitos íntimamente conectados que comprometen a la ética de la profesión médica: ¿padeció de locura u otra enfermedad mental Ludwig II? ¿Qué fundamentos éticos sustentaron el diagnóstico y peritaje del doctor von Gudden, que culminó en la destitución e internamiento del monarca?

\section{"El rey de cuento de hadas".}

Ludwig II de la Casa Wittelsbach, fue el hijo mayor del rey Maximiliano II, estricto, severo, atenido a reglas, y de la princesa Marie, religiosa, distante, poco afectiva. A los siete meses padece un cuadro febril severo de meses de duración, producto de una meningitis de su nodriza que le amamanta, por la cual ella muere. A los 17 años una enfermedad infecciosa grave incide en su bajo rendimiento en la universidad, donde alcanza a cursar algunas asignaturas que no influyen en su marcada preferencia por la lectura, el teatro, la música y arquitectura, predilecciones que expresan una tendencia al ensimismamiento reflexivo arrogante, generando incomprensión y mofa de sus padres. El 17 de marzo de 1864 muere súbitamente su padre. El mismo día es proclamado rey con solo 18 ańos de edad y, a la mañana siguiente, ante el gobierno pleno, presta juramento solemne de obediencia a la constitución: "Yo me entrego con todo mi corazón al trono..., de ello pueden estar seguros todos los bávaros"(5).

Su aspecto juvenil seductor inflama a las personas que lo circundan en los primeros tiempos: a su prima, la emperatriz Elisabeth "Sissi” de Austria, al apuesto Paul von Thurn und Taxis, a su institutriz Sybille Meilhaus, y subyuga a todo el pueblo bávaro. Rápidamente desconcierta al trabar amistad íntima con su idolatrado Richard Wagner, gastando sumas considerables de dinero, pagando sus deudas y ostentosas puestas en escena de sus óperas, siendo forzado por sus ministros a expulsarlo del país por su intromisión insólita en la política gubernamental, además de impulsarlo a fantasear en una utópica monarquía absoluta de "religión del arte", al estilo del absolutismo de Luis XIV de Francia, contraria a la legislación bávara. El desconcierto se torna en desencanto al distanciarse de sus funciones de regente del gobierno, rehuir de la capital München, a la que no tolera porque "allí he sufrido tanto", ausentarse de presidir ceremonias oficiales, no asistir personalmente a festividades populares, enclaustrarse en sus castillos, apartado de sus ministros, diplomáticos y políticos, producto de una exacerbada timidez altanera. Profundamente católico, acosado por sentimientos de culpa y asistido e impulsado por su confesor Ignatz von Dollinger, se compromete con su prima Sophie, hermana menor de "Sissi", compromiso que rompe ese mismo año de 1867, tras haber idealizado su relación como la escenificada entre "Elsa" y "Lohengrin", aunque desprovista de la "carnalidad" de la ópera.

Los dispendios económicos de las dos guerras en 
que se ve envuelto, muy a su pesar, de 1866 y 1870 , desatan cáusticas críticas contra su persona, por no presentarse públicamente respaldando a su ejército, y una amarga decepción para él, por perder parte de su rango de monarca al tener que afiliarse como miembro del imperio alemán, supeditándose al férreo mando del canciller Bismarck. Su desilusión lo impele esta vez a formar la sociedad secreta "Coalición", con adeptos leales escogidos encargados de instaurar una monarquía borbona absoluta "de bautizo"-dei gratia- que se remontaría hasta Luis IX "el santo", cuya rápida inefectividad lo desalienta e impulsa a retraerse más en sus palacios. Asiste a funciones de teatro de incógnito o decreta que sean ejecutadas para él sin público; ordena comidas para comensales que no están presentes - nobles antepasados franceses- con los cuales charla(6); sus servidores no deben osar mirarle a los ojos; pasea solitario por trineo en las noches contemplando la luna -"el Rey luna”-; cambia el día por la noche; restringe al máximo las relaciones protocolares con embajadores, miembros del gobierno y familiares: la última vez que ve a "Sissi" es 1881 . En 1870 irrumpe la enfermedad mental progresiva de su hermano Otto, que obliga a internarlo de por vida y, desde 1872 , queda a cargo del psiquiatra von Gud$\operatorname{den}(7)$.

\section{Furor apasionado por construir e incontrolab- le pasión erótica}

Su timidez juvenil se intensifica en una introvertida petulancia autoconsciente con marcada necesidad de dominio, control y vigilancia de su ambiente, que incrementa su incomunicación con el pueblo y ministros, cumpliendo sus funciones del reino a puerta cerrada. Un progresivo deterioro de su cuerpo se torna notorio, pierde hermosura, engorda, la mirada se trueca acechante, la falta de higiene y el engullir dulces desordenada y desmesuradamente tras provocarse vómitos causan la pérdida casi completa de su dentadura, que queda reducida a muñones, como anota el príncipe imperial prusiano Friedrich Wilhelm: "El rey Ludwig... ha perdido notoriamente su belleza: pálido, nervioso, inquieto"(8).

Habiendo transcurrido su infancia en el Palacio Hohenschwangau, y con los reyes Ludwig I y Maximiliano II como antepasados que erigie- ron fastuosos palacios, brota en Ludwig un frenesí por construir castillos, además de teatros, mansiones y avenidas, buscando sobrepasar en esplendor, lujo, suntuosidad a sus predecesores, absorbiéndolo hasta la exaltación - Neuschwanstein, Linderhof y Herrenchimsee. Abrumados sus ministros del gabinete encargados de las finanzas por sus desembolsos cuantiosos, incesantes y crecientes, comienzan a enviarle memorándums, señalándole los graves peligros económicos de la política de construcción ininterrumpida, escritos que entregan a sus sirvientes, medio que sustituye el contacto directo porque Ludwig decididamente lo evita.

Tras su frustrado noviazgo con Sophie se desata, plagado de sentimientos de culpa y compunción, una creciente fogosidad erótica abrasadora con varones de muy distinta edad, condición social, instrucción - actor Josef Kainz, barón von Varicourt-, miembros de su servicio personal o del regimiento de caballería privado, aun sujetos escogidos ad hoc por un intermediario para estos fines carnales. De duración disímil —breves, intermitentes, permanentes-, con términos abruptos o rupturas tormentosas, estas intimidades no solo significan despilfarros en regalos, sino desahogos intensamente pasionales, fantasías, voyerismo, masturbación asociada a prácticas violentas, castigos extravagantes contra sus partenaires, fiestas nocturnas acompañadas de ingesta de alcohol(9).

\section{Peritaje: anamnesis 1883-junio 1886}

Hacia 1883, la ausencia de vínculo del rey con sus ministros se intensifica. Funcionarios de confianza de menor rango del monarca, sirvientes, domésticos - Hesselschwert, Hornig, Welker, Mayr fueron criados y amantes - actúan como intermediarios de las misivas entregadas por su secretario oficial de gabinete. En el verano de 1885 la situación financiera y política del reino se torna desastrosa: gastos exorbitantes en la construcción de castillos, unido a repetidos rechazos de Ludwig a las propuestas de sus ministros de suspender todas las edificaciones; peor aún, él las multiplica justificándolas porque estas son "mi verdadera alegría en la vida”. Además, las circunstancias devienen particularmente preocupantes, porque las deudas no caen directamente sobre el Estado sino involucran a la Casa Real Witteslbach, lo que 
acarrea el riesgo político del escándalo que causaría una posible solicitud de demanda civil ante tribunales. A lo anterior se suma el descontento de la población bávara ante los derroches y alza de impuestos, las críticas de los diarios frente a la incapacidad del régimen de manejar la economía, la negativa de bancos extranjeros y financistas privados a continuar prestando dinero porque imponen una condición inapelable: que el rey paralice toda construcción, condición que éste desestima y rechaza absolutamente. La postura de Bismarck se adiciona, porque el canciller, siempre permisivo con Ludwig, enviándole anualmente importantes sumas de dinero, resuelve suspenderle todo crédito, insinuándole firmemente que entable negociaciones personales con su propio gobierno. Aparecen alusiones en la prensa a conductas atentatorias contra la moral por parte del rey - maltrato físico y psicológico a sus criados- y excentricidades, trascendiendo toda decencia.

a) Conducta de Ludwig 1886. Ludwig planea medidas extravagantes al iniciarse 1886, como robar un banco, formar un Contingent que le defienda de sus agresores que le quieran juzgar por insolvencia, al estilo de la policía secreta rusa, y transformarse a continuación en monarca absoluto. Su secretario personal intenta nuevamente conseguir dinero en Berlín y Paris, peticiones rechazadas porque la banca y prestamistas repiten la cláusula: cese de toda edificación; además, este dinero que busca obtener tiene el propósito de derrocar al gobierno constitucional y aun ayudar a formar con posterioridad un reino absolutista en la Islas Canarias. Impulsa a su leal Graf Dürckheim a redactar una defensa activa frente a la prensa internacional que fustiga la situación económica de Baviera, artículo que necesitó admitir que suspendería las construcciones, escrito que disgustó a Ludwig. En enero responde enérgicamente a su ministro del Interior que no le interesa conseguir dinero para pagar deudas sino para continuar construyendo, y en abril endurece más reciamente su postura ante su primo príncipe Ludwig Ferdinand, con quien le une una afinidad especial, quien le manifiesta inequívocamente su rechazo. En marzo está a punto de ser víctima de una estafa de 25 millones de marcos por la embaucadora internacional Nanette Wagner, quien asegura solucionar sus deudas mediante documentos ban- carios, estafa burda que es impedida por la Dirección de Policía de München, institución que insinúa la imprudencia casi infantil del monarca en el manejo de sus negociaciones $(10,11)$.

b) Comportamiento del gobierno 1886. En julio de 1885, una reunión privada solicitada por el príncipe Luitpold y su hijo Ludwig con los ministros Lutz y Craislheim por los desembolsos que afectan a la Casa Wittelsbach resuelve no forzar la legalidad ante los caprichos del rey, aunque empieza a considerarse su incapacidad para gobernar. En agosto y diciembre los nuevos ultimatos del monarca por endeudar al estado bávaro son rechazados por el gobierno, a los que se suma el partido opositor por la impopularidad de esa medida, aceptándose pagar solo a través de la renta privada de Ludwig, rechazos que desatan la ira del rey.

En enero de 1886 el primer ministro Lutz vuelva a debatir la eventualidad de una abdicación o destitución. En febrero, en nuevas deliberaciones con el sucesor del rey, el príncipe Luitpold se compromete, si se le eligiera como regente, a mantener al gobierno y partidos políticos en sus puestos: ambos lados se beneficiarían, Luitpold ascendería y defendería su familia real, Lutz conservaría el poder político.

La suma de eventos de 1885/1886 impulsa al gabinete a dar otro paso: determinar que se examine el estado psicológico de Ludwig. El 23 de marzo, el psiquiatra profesor Bernhard von Gudden, en reunión privada con los ministros Lutz y Craislheim, asegura que el rey padece de una locura primaria (originär verrückt) que lo incapacita para gobernar, y él redactaría un peritaje médico sin necesidad de examen directo por innecesario e imposible. Al comunicar las conclusiones del psiquiatra, estas son impugnadas por algunos ministros, parlamentarios y su médico personal, Max von Löwenfeld, justificando las conductas como excentricidades, fantasías, extravagancias.

Financieramente, sus deudores se tornan en personalidades dispuestas a cobrar en tribunales; moralmente, testigos de escándalos difunden su reprobación ante estas conductas impúdicas; su primo, el príncipe Ludwig Ferdinand, no consigue préstamo alguno en el extranjero. El 30 de 
abril Lutz y el presidente de los diputados de oposición von $\mathrm{Ow}$ vuelven a discutir la posibilidad de una abdicación, pero el príncipe Luitpold reitera su oposición, porque las deudas y deshonra incriminarían a su familia(12).

En mayo de 1886 la situación se tensa al extremo, por las demandas concretas del gobierno a Ludwig: la obtención de dinero es impracticable sin la cesación de las edificaciones, un cambio de gabinete no soluciona las dificultades financieras, necesidad de su aparición en público en la capital München y cambio de las conductas del rey con sus sirvientes. Iracundo, Ludwig desecha todas las indicaciones, exacerbando sus exigencias: continuar sus construcciones es "la más alta felicidad de mi vida", ordena una renovación radical de gabinete y desprecia las quejas sobre sus comportamientos por ser insolentes para su dignidad. Bismarck declina intermediar porque Prusia no puede inmiscuirse en los asuntos de Baviera. Se trata de un problema triple: de Estado, de la dinastía y de los ministros.

17 de mayo, nuevo encuentro del doctor von Gudden con los ministros: él reafirma sus juicios anteriores, aunque reconoce que "el rey puede ocultar con especial destreza" sus anomalías, lo que impide fiarse de sus anuncios pregonados de dimisión o suicido y, además, destituyéndolo se acata estrictamente la Constitución bávara. Al día siguiente se determina destituir al rey y seguir el procedimiento dispuesto por la ley de 1818 de Baviera: elaborar un peritaje oficial con base en las declaraciones certificadas por testigos presenciales de las conductas del rey, nominar tres psiquiatras como coautores del documento y encargar la redacción al profesor von Gudden. En la noche del 7/8 de junio, von Gudden redacta el manuscrito, que es ratificado por los psiquiatras y leído el 9 de junio en sesión solemne del gabinete, ocasión en que el príncipe Luitpold es proclamado Regente por inhabilidad de Otto a suceder a Lud$\operatorname{wig}(13,14)$.

\section{Peritaje neuropsiquiátrico}

Consta de tres secciones: antecedentes, descripción de las conductas anormales y conclusiones irrevocables. Las consideraciones introductorias demuestran la deferencia irrestricta a la dignidad del rey, el carácter inapelable del veredicto y la justificación de que el documento se elaborara sin que la comisión examinara personalmente al mandatario.

"Por doloroso que resulte para los médicos firmantes abordar la valoración de la condición espiritual de Su Majestad su Rey, deben obedecer las órdenes recibidas y por la presente, refiriéndose expresamente al juramento que han prestado, plenamente conscientes de su grave responsabilidad, se entrega el peritaje requerido obedeciendo su deber y conciencia, en el que advierten que una entrevista personal con Su Majestad sobre qué más explicar sería superflua, se vuelve irrazonable, innecesaria con los archivos disponibles ..." (15).

Seguidamente detalla los comportamientos que motivaron la elaboración del peritaje (cuadro 1). La resolución definitiva recapitula inequívocamente la condición mental irrecuperable de Ludwig:

"Su Majestad está en un grado muy avanzado de perturbación psíquica, y evidentemente sufre de esa forma de locura que es bien conocida por los psiquiatras de experiencia que se denomina paranoia (locura);

Debido a esta forma de enfermedad, su desarrollo gradual y progresivo, y su duración ya muy larga, que se ha extendido durante una cantidad considerable de varios años, Su Majestad ha de ser declarado incurable y con una perspectiva cierta de deterioro aún mayor de las facultades mentales;

Debido a la enfermedad, la libre voluntad de Su Majestad está completamente suprimida, se le debe considerar como inhabilitado para ejercer el gobierno y este impedimento no solo durará más de un año, sino de por vida" (16).

\section{Peritaje: catamnesis}

El diario Bamberger Zeitung publica el 11 de junio un escrito de Ludwig (?) dirigido al pueblo bávaro, que la censura rápidamente confisca: "El príncipe Luitpold intenta elevarse a la calidad de Regente de mi país sin mi consentimiento, y mi hasta ahora ministerio ha engañado a mi pueblo con noticias falsas sobre mi estado de salud y pre- 
para actos altamente sediciosos"(17).

Poco antes el gobierno nombra una "Comisión Estatal" para comunicar al rey la resolución oficial del gobierno del Regente Luitpold de Baviera. Esta se dirige en dos oportunidades al Castillo Neuschwanstein donde reside Ludwig. Primera (9 junio): ministro Craislheim, doctor von Gudden, doctor Müller, dos curadores, cuatro enfermeros; son repelidos, encerrados, custodiados por soldados leales en cuartos de servicio, siguiendo órdenes de Ludwig —enfurecido, inquieto, con ideación suicida-; sin saberlo Ludwig, al día siguiente son liberados para retornar a la capital obedeciendo mandatos de München. Segunda (11 junio): doctor von Gudden, doctor Müller, cuatro enfermeros, chaleco de contención, correas de cuero, cloroformo; Ludwig los recibe objetando a von Gudden su diagnóstico, afirmando jamás haber sido examinado personalmente; efectivamente, es la primera ocasión en que Ludwig $\mathrm{y}$ von Gudden dialogan uno frente al otro - casualmente- mientras aguardan el coche cerrado que lo conducirá al encierro(18). Dos días después, von Gudden revalidará su diagnóstico por teléfono a München desde el lago Starnberg, minutos antes de morir: "un examen personal sólo confirmó la evaluación escrita”(19).

La autopsia es ejecutada por expertos (15 junio) (cuadro 2). Las muertes de Ludwig II y Bernhard von Gudden permanecen en la incertidumbre. Los hechos comprobados son: 1) Los relojes de ambos revelan una diferencia en su detención, por lo que es probable que el doctor von Gudden muriera antes. 2) Von Gudden muestra hematomas en su cara y frente. 3) Ludwig II medía 1.91 metros y era bastante más joven que su médico. 4) Ludwig había expresado inequívocas ideas de suicidio hacía poco tiempo. 5) No se encontró agua en los pulmones de Ludwig, lo que permite suponer que no murió ahogado.

Existen algunas posibilidades, pero las dos más probables son las siguientes. Ludwig quiso suicidarse por lo que, al tratar de impedirlo von Gudden, lo golpeó violentamente y tras su muerte en el lago, se quitó la vida según lo había planeado. Por otra parte, unos tripulantes que estaban en un bote en las cercanías habrían intentado infructuosamente convencerlo de escaparse a la frontera austríaca tras la muerte de von Gudden.

\section{Diagnóstico: peritaje}

a) Base del peritaje. Su fuente radica en su totalidad en los antecedentes aportados voluntariamente por personas cercanas al rey, protocolizados y firmados, aunque hubo testigos que se abstuvieron o íntimos al rey que no fueron entrevistados (su médico personal Max von Löwenfeld, Elisabeth "Sissi" de Austria, baronesa Spera von Truchseß). b)Entrevista psiquiátrica. Se descarta por considerarse innecesaria por la cantidad y calidad de la documentación suministrada y la imposibilidad de llevarse a efecto ¿previniendo posible rechazo o manipulación de Ludwig? c) Estructura del peritaje. Frecuente uso de lenguaje no técnico destinado a describir vivencias, conductas, afectos, cognición y voluntad, registro de la herencia solo inmediata, tendencia a presuponer intenciones o conjeturar motivos del actuar, correlacionar fenómenos heterogéneos, silenciar capacidades conservadas como responder la correspondencia a sus ministros, callar sobre esferas de la vida cotidiana ejecutadas apropiadamente(20). dI Nosología psiquiátrica. Empleo de los conocimientos últimos de la psiquiatría alemana vigente, provenientes de la monomanía de Esquirol y que, elaborada por Feuchtersleben, Griesinger y Snell, desemboca en la primäre Verrücktheit o paranoia; lo nuclear radica en los pensamientos enajenados en cuanto primarios, incomprensibles, inmodificables y causantes etiológicamente del comportamiento y la enfermedad(21-23).

\section{Diagnóstico: 1886 hasta actualidad}

Desde la muerte de Ludwig II, el diagnóstico de su trastorno ha sido motivo de un intensísimo debate en psiquiatría(24-28). Por una parte, el doctor Müller, acompañante de la detención y traslado del rey, objetó la caminata de von Gudden al borde del lago por el alto riesgo de suicidio; reconoció asimismo haberse equivocado en su juicio inicial sobre Ludwig, aunque tiempo después se desdijo en el informe oficial. Por otra, los tres psiquiatras que subscribieron el diagnóstico junto a von Gudden ratificaron su posición posteriormente ante una comisión ad hoc del parlamento. Además, si bien plantear un diagnóstico retrospectivamente e impedido de efectuar un 
examen al rey está sujeto a insuficiencias técnicas casi insuperables, con el correr de los años se ha ido acumulando valioso material gracias a la apertura progresiva de los archivos secretos de la Casa Wittelsbach. Finalmente, von Zerssen ha revisado los diagnósticos emitidos desde 1910 hasta 2010 por 21 especialistas, utilizando las categorías del ICD-10 para su evaluación objetiva, distinguiendo entre criterios operacionales de diagnóstico y comorbilidad, diferencia habitualmente no tomada en consideración; los 24 diagnósticos planteados son particularmente idiosincráticos, heterogéneos, contradictorios entre sí, aunque cerca de la mitad se inclina por una esquizofrenia paranoide, o sea, optan por ratificar el diagnóstico de von Gudden. El autor sostiene que era un diagnóstico erróneo, porque la patología del rey no radicaba en su pensamiento racional, sino en la coexistencia de distintas anomalías que alteraban su comportamiento consigo mismo, los demás y su vida pública(29-31) (cuadro 3).

Utilizando el DSM-5 se plantean los siguientes diagnósticos(32).

1) Proceso orgánico que compromete las áreas frontal y temporal, que permite postular: enfermedad neurodegenerativa (inicios de trastorno neurocognitivo frontotemporal) y/o secuela de meningitis infantil (trastorno de personalidad orgánica) (cuadro 4).

2) Trastorno de personalidad esquizotipica (ideas de referencia, creencias extrañas, experiencias perceptuales inusuales, ideas paranoides), si se descarta previamente la personalidad orgánica como secuela de meningitis infantil(33).

3) Abuso de alcohol.

4) Trastorno del control de impulsos.

5) Trastorno del hábito del comer.

6) Locura imperial (altanería grandiosa) (no catalogada en la nosología actual)(34).

\section{Diagnóstico y peritaje: antecedentes éticos}

Entender los dilemas éticos, involucrados tanto en el diagnóstico como en el peritaje de Ludwig II ejecutados por von Gudden, precisa considerar previamente los siguientes ámbitos.

A) Solamente a mediados del siglo XX se produjo un "giro ético" en medicina que provocó una efervescencia en filosofía, derecho, política y ciencias humanas, o, en palabras de Toulmin, "la medicina (bioética) ha salvado a la ética” (35).

B) A diferencia del siglo XIX, fue en el siglo XX que se cuestionó fuertemente la noción de sujeto racional dueño de sí mismo - "giro del sujeto"que constituía la base del pensar científico, médico y humanista $(36,37)$.

C) La época moderna nació con la nuova scienza de Galileo, la cuantificación radical de los fenómenos por medio de la mensuración(38), vale decir, un tipo de pensar, el calculador (Verrechnen), que da prioridad a la actitud objetivadora, dominadora, instrumental, clasificatoria(39); en otras palabras, no importa la "esencia" de las cosas, el "ser" de la realidad, sino su objetividad, esto es, positivización radical —el objeto que está "ahî" y en tanto que "está ahî" (40).

\section{Ética del diagnóstico}

Diagnosticar proviene del griego diagignôskein, que los médicos usaron no solo como un discernir o distinguir, sino un conocer recorriendo o penetrando en la profundidad de las afecciones(41). La medicina surge en Grecia cuando el sanador empírico asume un compromiso o xyngraphé al momento de su iniciación, acatando preceptos que se materializan en el Juramento, pacto que asegura avalar reglas jurídicas, pero en especial y más importante, apropiarse e incorporar normas morales, que en Epidemias I, 11 se explicita como "primum non nocere", "ejercitarse respecto a las enfermedades en dos cosas, ayudar o al menos no causar daño"(42). El primum non nocere engarza la prescripción moral de no-maleficencia ("no causar daño") con el precepto ético de beneficencia ("ayudar"), empero quedando claro que la beneficencia es la máxima fundamental y decisiva al aclararlo a continuación como el logro del máximo bien, la máxima utilidad, hacer el bien (opheleîn), y luego agrega otro constituyente "según mi capacidad y recto entender" (43). Al proceder a diagnosticar von Gudden fue claro en su obediencia y respeto a los dos ámbitos o 
terrenos que involucra el com-prometerse con su profesión de psiquiatra cuando se asume el Juramento, aunque priorizando el precepto de beneficencia. Por una parte, acató con inexorable rigor su alto ideal de perfeccióm moral de "ayudar", puesto que buscó sin vacilar el "bien" de Ludwig II, vale decir, no por motivos circunstanciales, no por satisfacción o beneficio personal, sino por la convicción de que el precepto intrínsecamente encarna el bien; es la convicción íntima la que no admite excepciones, es incondicionada y unívoca, no tolera acomodos ocasionales, es incompatible con cualquier tipo de componendas, no se somete a los caprichos del tiempo o de las circunstancias. Por otra parte, von Gudden actuó sin dudar según "su" opinión y recto valorar, según "su" competencia y "su" ajustado razonar, decidió diagnosticar y emitir el diagnóstico en acuerdo a lo que "su" entendimiento daba por cierto era lo mejor para el rey; fue el ideal de perfección moral de ayudar y no dañar de von Gudden mismo, no aquel que Ludwig II estimara como su aspiración de perfección el que determinó la naturaleza y profundidad de su obediencia incondicionada a las obligaciones. Por un lado, ejercer el bien en acuerdo a la moralidad interna del precepto y, por otro, es el psiquiatra von Gudden el que decide(44).

\section{Ética del peritaje}

La profesión médica nace como una professio que deriva de profiteor, esto es, proclamar, confesar abiertamente, hacer voto. El significado originario es confesión pública, consagración, promesa. Este origen histórico la ubica en relación íntima con la consagración religiosa (professio monastica) $y$, por ello, se la honra con una fuerte responsabilidad moral y una impunidad jurídica completa o relativa(45). Weber señaló que la profesión tiene además otro sentido, proveniente del alemán. Como profesión (Beruf) está emparentada con Ruf, llamada, y Berufung, vocación(46). Von Gudden entendió su quehacer como psiquiatra como voca-ción (vocatio), llamada que hace su conciencia por medio de una suerte de voz interior (vocis) para atenerse a sus ideales, tanto personales íntimos, como proyectos profesionales y normas inherentes a la sociedad(47). Al llevar a cabo el peritaje de Ludwig, los mandatos de su conciencia, su cum-scientia, oscilaron entre dos ti- pos de responsabilidad: la responsabilidad frente a sí mismo y la responsabilidad frente a los otros; la responsabilidad moral y la responsabilidad jurídica; obligación para consigo y obligación para los demás; la autoconciencia y la conciencia social. Pero ambas conciencias no son iguales. La conciencia ante leyes (Gesetz) significa que estas son puestas y propuestas (vor-setzen) por la medicina, pero especialmente por la sociedad(48), por tanto, difiere de su conciencia propia del "yo juzgo" puesto que este "yo juzgo" es un yo idéntico a sí mismo, se auto-posee sin residuo, es transparente para sí mismo y, así, es responsable de sus actos; en otros términos, al disponer de su propio ser a su libre arbitrio, aprehende las normas, médicas y jurídicas, que están sustentando el peritaje, tal como ellas son en sí, las refleja fiel, adecuada, límpidamente como espejo. Acatar las leyes jurídicas presupone que su conciencia las aprehende en toda su pureza - lo legal - sin distorsiones provocadas por ambiciones, deseos circunstanciales, apetencias políticas, arreglos sociales acomodaticios.

\section{“Quiero permanecer un eterno enigma para mí y para los otros"}

1) La condición espiritual del Rey Ludwig II es motivo de controversia psiquiátrica, ética, jurídica, política, histórica y del pensar hasta la actualidad, y ha obligado a replantearse los fundamentos de cada ámbito involucrado, sin encontrar respuestas definitivas; empero, ha obligado a profundizarlos y modificarlos sustancial y decisivamente, tanto el principio de beneficencia como el sujeto que sabe de sí como fundamento del saber de la realidad(49).

2) Acudiendo a Binswanger, se puede entender a Ludwig como un modo de existencia fracasada o malograda (mißglückt), configurando una manera de ser en el mundo extra-vagante (Ver-stiegenheit), que se jugó por la elevación desaforada, voluntariosa, empecinada, degradada (Stiegenheit) de la "decisión" (Ent-scheidung), sin asentarse en la "experiencia" (Er-fahrung) como suelo firme de sustentación, desde donde se desbarrancó sin retorno(50-53). Esto significa no reducir a Ludwig solo a la categoría de deficiencia, patología, carencia o trastorno clasificable al interior de una nosología, sino de persona, poseedora de dignidad y 
objeto de respeto.

3) El profesor Bernhard von Gudden fue un destacado neuropsiquiatra especializado en patología cerebral, impulsor de su discípulo Kraepelin para que escribiera su Compendium der Psychiatrie(54), introductor del principio de "no restraint", empatía y tolerancia hacia los pacientes internados. Quizás confundió los roles de experto forense y terapeuta empático con su paciente Ludwig II en las orillas del lago Starnberg, confusión que no le permitió juzgar en toda su gravedad sus impulsos suicidas, como le advirtió su ayudante, puesto que estaba profundamente comprometido en asistirlo emocional, íntima y personalmente, conflicto que finalmente le costó la vida a manos del rey(55).

4) Ricoeur ha planteado una diferencia sustancial entre lo personal y lo legal, lo íntimo y lo social que, en los acontecimientos del Rey Ludwig II, se puede formular de la siguiente manera. Mientras en el acto médico su finalidad corta es resolver un sufrimiento, es una solicitud que tiene por meta remediar el sufrimiento, en el acto jurídico su finalidad corta es resolver un conflicto, un antagonismo, una crisis y su finalidad larga es restablecer el vínculo social, instaurar la paz(56).

5) Hare ha recordado que a la existencia humana le es inherente un moral gap o fracaso moral que, al final, supera, doblega y obliga a todo médico, vale decir, nunca se logra la realización moral completa deseada y buscada con ahínco(57). Heidegger apunta a que constituye una condición que nos es inevitable, no solo como médicos sino como seres humanos; por un lado, somos "facticidad", ya que siempre-estamos arrojados-en-el-mundo que nos precede y al cual estamos implantados porque no somos el-fundamento-originario-de-nuestro-ser y, por otro, somos pro-yecto-de-ser-propio, lanzados al futuro $(\mathrm{Zu}$-sein), siempre expelidos en pos de nosotros mismos, que jamás alcanzaremos y nunca obtendremos, así, nuestra realización definitiva se nos escapará $(58,59)$. Ludwig II y von Gudden expresan esta estructura de ser de manera dramática.

Peritaje psiquiátrico del Rey Ludwig II de Baviera (modificado desde Förstl H, König Ludwig II. als Patient. $Z$ Bayer Landesgesch 2011; 74(2): 331-346).

\section{Procedimiento}

Por encargo del presidente del gabinete Dr. Johann Freiherr von Lutz y con la venia del futuro Príncipe Regente Luitpold, el 8 de junio de 1886 el profesor Bernhard von Gudden y los psiquiatras Hubert Grashey, Friedrich Wilhelm Hagen y Max Hubrich declaran que el presente peritaje de Su Majestad Su Rey Ludwig II. toma las precauciones para que el contenido, las medidas y procedimientos no devengan del dominio público como protección a la honra del rey Ludwig, siguiendo las directivas de la Constitución de $\mathrm{Ba}$ viera Título II $\$ 11$.

El documento se sustenta en informes de actas del gobierno proporcionados por el presidente del gabinete Dr. Johann Freiherr von Lutz a la comisión médica el día 5 de junio de 1886. a] Declaraciones protocolizadas de tres servidores del rey, el maestro de caballerizas Karl Hesselschwert (18.05.86), el encargado personal de servicio real Adalbert Welker (19.05.86), el secretario ministerial Heinrich Thelemann (25.05.86). b] Informes escritos de los antiguos secretarios de gabinete Friedrich von Ziegler (05.06.86) y Ludwig August von Müller (03.06.86). c] Informe escrito del maestro de cuadra Richard Hornig (04.06.86). d] Cartas de Su Majestad Su Rey Lugwig II. e] Ausencia de examen psiquiátrico presencial del rey ante los psiquiatras firmantes.

\section{Hallazgos psiquiátricos}

- Herencia: Princesa Alejandra tía del Rey Ludwig, enfermedad mental incurable; trastorno psíquico incurable de su hermano Otto.

- Angustia: intensa timidez vergonzosa ante la gente, evitación de obligaciones sociales, como almuerzos y fiestas populares, repudio a la capital München, exigencia de funciones teatrales destinadas sólo para él sin público.

- Errores de los sentidos y falsos reconocimientos (alucinaciones e ilusiones), hipersensibilidad a los ruidos, suspicacia acuciosa y desconfiada plagadas de temor, indicios de alucinaciones visuales, conversaciones con huéspedes imaginarios (Luis XIV, Madame de Pompadour...). 
- Agitación impaciente de la motilidad: gesticulaciones encantadoras y muecas grotescas ante el espejo, dar vueltas enfurecido y luego permanecer inmóvil ante una mancha, jugar durante horas con un rizo del cabello.

- Irritabilidad y agresividad: emisión de breves expresiones injuriosas contra la reina madre, explosiones verbales de rabia y acciones violentas corporales contra la servidumbre, así como amenazas de encerrarlos en un calabozo (que nunca se llevaron a cabo).

- Representaciones delirantes: veneración de ciertos lugares y desprecio de otros, idea de la Coalición, vale decir el reclutamiento de una banda de varones que deben restituir el reinado absolutista, la introducción supuestamente proyectada del ceremonial chino de palacio, ambas y otras deben ser instituidas así como una serie de otros ejemplos que no nacen simplemente de la actividad de la fantasía, sino de una pérdida de la realidad por lo menos temporal, adoración de Luis XIV.

- Al pasar se mencionan indicios de descuido de la persona del Rey, tocante a los hábitos del comer y a la suciedad resultante de su vestimenta.

Autopsias de Ludwig II y Bernhard von Gudden del 15 de junio de 1886 (adaptado desde Zerssen D von. Der bayerische "Märchenkönig" Ludwig II. Nervenarzt 2010; 81: 1368-1378).

\section{Ludwig II}

Engrosamiento acentuado bilateral frontal de la duramadre y aracnoides.

Atrofia bilateral de las primera, segunda y tercera circunvoluciones frontales.

Sustancia gris neocortical estrechada.

Cerebro pequeño de 1.394 gramos.

Ganglios basales, cerebelo y ventrículos normales.

Asimetría y reblandecimiento local de zonas del cráneo especialmente orbital.

No se encontró agua en los pulmones.

\section{Bernhard von Gudden}

Rasguños profundos en su cara.

Hematomas superficiales en su frente.
Diagnósticos psiquiátricos emitidos por especialistas modernos. (Fuentes: Zerrsen v. (2010); Häfner y Sommer (2011); Zerrsen v. (2013); Steinberg (2018). En cursiva los diagnósticos más probables en la actualidad).

1. Paranoia, perteneciente al grupo de la esquizofrenia paranoide

2. Trastorno de personalidad esquizotipica

3. Enfermedad fronto-temporal(trastorno de personalidad orgánica)

4. Trastorno neurocognitivo de inicio.

5. Parafrenia afectiva

6. Fobia social

7. Trastorno de personalidad narcisista

8. Trastorno de personalidad antisocial

9. Trastorno de personalidad limítrofe

10. Trastorno de personalidad histriónica

11. Locura imperial (Cäsarenwhansinn) (sindrome bybris)

12. Locura moral

13. Neurosífilis

14. Dependencia o furia de construcción

15. Homosexualidad

16. Delirio de los masturbadores

17. Trastorno del control de los impulsos

18. Abuso de alcohol, cloral, opio

19. Obesidad, trastorno del hábito del comer

20. Variante normal de la personalidad

21. Fanatismo (variedad Lohengrin)

Trastorno frontotemporal (posible del rey Ludwig II) (Modificado de: Zerrsen D v. Der bayerische "Märchenkönig" Ludwig II. Nervenarzt 2010; 81: 1368-1378).

\section{General}

- Cambio del modo de ser con descuido progresivo de sus deberes familiares, gubernamentales y financieros (conducta pseudopsicopática).

\section{Especifico}

- Alteraciones de la conducta social con falta de 
empatía, falta de consideración, ausencia de arrepentimiento cuando ofende o maltrata a otras personas.

- Sexualidad desinhibida, dependencia del comer.

- Aumento de consumo de alcohol.

- Estereotipias de movimiento.
- Labilidad afectiva con irritabilidad aumentada. - Incontinencia afectiva con irrupciones agresivas. - Predominio de la emocionalidad negativa, especialmente ansiedad; suicidalidad.

- Descuido de su persona (especialmente antes y después de comidas opíparas).

\section{Referencias}

1. Schiller F. Sämtliche Werke Band 2: Dramen 2. Berlin: Carl Hanser; 2004.

2. Wöbking W. Der Tod König Ludwigs II. von Bayern. Eine Dokumentation. Förg: Rosenheim; 1986

3. Hacker R. Ludwig II. von Bayern. Krankheit, Krise und Entmachtung-Quellentexte. Z Bayer Landesgesch 2011; 74(2): 481-725.

4. Foucault M. Naissance de la biopolitique. Cours au Collège de France. 1978-1979. Paris: Gallimard; 2004.

5. Hacker R. Ludwig II. von Bayern in Augenzeugenberichten. 3. Aufl. München: dtv; 1986.

6. Wagner C. Die Tagebücher in zwei Bände: Zweiter Band 1877-1883. Berlin: Holzinger; 2015.

7. Häfner H. Dynastic, social, psychological and psychiatric aspects of the Bavarian royal drama of 1886. Can Soc Sci 2015; 11: $1-22$.

8. Böhm G von. Ludwig II., König von Bayern. 2. Aufl. Berlin: Engelmann; 1924.

9. Obermeier S. Das Geheime Tagebuch König Ludwigs II. von Bayern. 2. Aufl. München: F.A. Herbig; 2000.

10. Zerssen D von. Der bayerische “Märchenkönig” Ludwig II. Seine letzten Jahre aus psychiatrischer Sicht. Nervenarzt 2010; 81: 1368-1378.

11. Förstl H, Immler G, Seitz M, Hacker R. Ludwig II, King of Bavaria: A royal medical history. Acta Psychiatr Scand 2008; 118: 499-502.

12. Hacker R. Ludwig II. von Bayern, die Königskrise von $1885 / 86$ und der Weg zur Regentschaft. Z Bayer Landesgesch 2011; 74(2): 347-430.

13. Immler G. Krankheit, Krise und Entmachtung des Märchenskönigs. Akademie Aktuell 2011; 04: 18-21.

14. Häfner H. Ein König wird beseitigt. Ludwig II. von Bayern. 2. Aufl. München: Beck; 2011.

15. Gudden B von, Hagen FW, Grashey H, Hubrich M. Ärtzliches Gutachten über den Geisteszustand Seines Majestät des Königs Ludwig II. von Bayern. En: Wöbkin W. Der Tod Ludwigs II. von Bayern. Eine Dokumentation. Rosenheim: Alfred Förg; 1986: 306-324.

16. Kommission für bayerische Landesgeschichte. König Ludwig II. von Bayern. Krankheit, Krise und Entmachtung. Zeitschrift für bayerische Landesgeschichte. Band 74 [Heft 2]. München: C.H. Beck; 2011

17. Häfner H. Ein unzurechnungsfähiger (?) König an einem Wendepunkt deutscher Geschichte-Ludwig II. von Bayern. Jahrbuch der Heidelberger Akademie der Wissenschaften für 2004-2005: 37-55.

18. Müller FC. Die letzten Tage Ludwigs II. Nach eigenen Erlebnissen geschildert von Dr. med. Franz Carl Müller. Süddtsch Monatsch 1929; 26: 769-840.

19. Kapfhammer HP. Der König und der Psychiater. Nervenarzt 2011; 2: 597-598.

20. Hippius H, Steinberg R. Guddens Kollegialsgutachten über Ludwig II. im Wissen seiner Zeit. Nervenarzt 2019; 90: 950-953.

21. Kendler KS. Tracing the roots of Dementia Praecox: the emergence of Verrücktheit as a primary delusional-hallucinatory psychosis in german psychiatry from 1860 to 1880. Schizo Bull 2020. DOI:10.193/schbul/sbaa039.

22. Berrios GE, Porter R. A history of clinical psychiatry. London: The Athone Press; 1995.

23. Berrios GE. The history of mental symptoms. Descriptive psychopathology since the Nineteenth Century. Cambridge: Cambridge University Press; 1996.

24. Förstl H. König Ludwig II. als Patient. Z Bayer Landesgesch 2011; 74(2): 331-346.

25. Häfner H, Sommer F. War das psychiatrische Gutachten B. von Guddens über König Ludwig II. von Bayern korrekt? Nervenarzt 2011; 82: 611-617.

26. Kaltenstadler W. War Ludwig II. geisteskrank? Kritische Anmerkungen zum Gutachten von Prof. Dr. med. B. von Gudden. Dtsch Med Wochenschr 2011; 136: 2684-2691. DOI 10.1055/s-0031-129286. 
Las perplejidades éticas del Rey Ludwig II de Baviera: locura, extravagancia y profesión médica - Gustavo Figueroa

27. Häfner H. Das psychiatrische Gutachten Bernhard von Guddens und die Entmachtung König Ludwigs II. von Bayern 1886. Ein Kommentar zum Beitrag von R. Steinberg in Der Nervenarzt 01/2019. Nervenarzt 2019; 2: 944-949.

28. Steinberg R, Falkai P. Was King Ludwig II of Bavaria misdiagnosed by Gudden and his colleagues? Europ Archiv Psychiatry Clinic Neuroscience 2020; DOI: https://doi.org/10.1007/s00406-020-01161-8.

29. World Health Organization. The ICD-10 Classification of Mental and Behavioural Disorders. Clinical descriptions and diagnostic guidelines. Geneva: World Health Organization; 1992.

30. Steinberg R. Guddens Diagnose über Ludwig II. aus zeitgenössischer und heutiger psychiatrischer Sicht. Nervenarzt 2019; 90: 62-68.

31. Zerssen D v. Die Vorzüge einer modernen operationalen Diagnostik psychischer Störungen. Der Fall des Bayernkönigs Ludwig II. - ein Beispiel aus der biographischen Forschung. Nervenarzt 2013; 84: 615-623. DOI 10.1007/s00115-0123548-z.

32. American Psychiatric Association. Diagnostic and Statistical Manual of Mental Disorders. Fifth Edition. DSM-5TM. Washington: American Psychiatric Publishing; 2013.

33. Hacker R, Seitz M, Förstl H. Ludwig II. von Bayern-schizotype Persönlichkeit und frontoาtemporale Degeneration? Dtsch Med Wochenschr 2007; 132: 2096-2099. DOI 10.1055/s-2007-985648.

34. Zerssen D von. Der “Cäsarenwahnsinn"-Wahrheit oder Legende? Fortschr Neurol Psychiatr 2011; 79(3): 152-160.

35. Toulmin S. How medicine saved the life of ethics. Perspec Biolog Med (Chicago) 1982; 25: 736-750.

36. Rodríguez R. Del sujeto y la verdad. Madrid: Síntesis, 2004.

37. Foucault M. L 'herméneutique du sujet. Cours au Collége de France. 1981-1982. Paris: Seuil/Gallimard; 2001.

38. Ortega y Gasset J. Vicisitudes en las ciencias. En: Ortega y Gasset J. Obras Completas. Tomo IV (1929-1933). Sexta edición. Madrid: Revista de Occidente; 1966: 63-68.

39. Heidegger M. Wissenschaft und Besinnung. En: Vortäge und Aufsätze. 5.Aufl. Pfullingen: Neske; 1967: 41-66.

40. Zubiri X. Naturaleza, historia, Dios. Buenos Aires: Poblet; 1948.

41. Laín Entralgo P. El diagnóstico médico. Historia y teoría. Barcelona: Salvat; 1982.

42. Gracia D. Primum non nocere. El principio de no-maleficencia como fundamento de la ética médica. Madrid: Instituto de España, Real Academia Nacional de Medicina; 1990.

43. Tratados hipocráticos. I. Madrid: Gredos; 1990.

44. Figueroa G. Tribulaciones éticas del Covid-19: lo sobrecogedor siniestro, la responsabilidad existencial y medice, cura te ipsum. Rev Med Chile 2020; 148: 1668-1673.

45. Figueroa G. Responsabilidad profesional: máximos, mínimos, excelencia y veracidad. Rev Med Chile 2006; 134: 251-257.

46. Weber M. Politik als Beruf, Wissenschaft als Beruf. Berlin: Dunker \& Humblot; 1959.

47. Figueroa G. Los cuestionamientos éticos de Freud: psicoanálisis, existencia y muerte. Acta Bioethica 2020; 26(1): 17-28.

48. Heidegger M. Das Ding. En: Vorträge und Aufsätze. 5. Aufl. Pfullingen: Neske; 1967: 157-175.

49. D’Agostini F. Analíticos y continentales. Guía de la filosofía de los últimos treinta años. Madrid: Cátedra; 1997.

50. Binswanger L. Drei Formen mißglückten Daseins. Verstiegenheit, Verschrobenheit Manieriertheit. Tübingen: Niemeyer; 1956.

51. Binswanger L. Vom anthropologischen Sinn der Verstiegenheit. En: Straus E, Zutt J, Hrsg. Die Wahnwelten (Endogene Psychosen). Frankfurt: Akademische Verlagsgesellschaft; 1963: 148-154.

52. Blankenburg W. Grundsätzliches zur Konzeption einer anthropologischen Proportion. Z f Klin Psychol Psychothe 1972; 20: 322-323.

53. Figueroa G. El análisis existencial de la anorexia nerviosa: de la ciencia psiquiátrica a su fundamentación. Revista Mexicana de Trastornos Alimentarios/Mexican Journal of Eating Disorders 2012; 3: 45-53.

54. Kraepelin E. Compendium der Psychiatrie: Zum Gebrauche für Studierende und Ärzte. Leipzig: Abel; 1883.

55. Steinberg R, Hippius H. Bernhard von Gudden zum 125. Todestag. Nervenarzt 2011; 82: 599-610. DOI $10.1007 /$ s00115-011-3295-6.

56. Ricoeur P. Philosophie, éthique et polithique. Paris: Seuil; 2017.

57. Hare JE. The moral gap: Kantian ethics, human limits, and God's assistance. Oxford: Clarendon Press, 1996.

58. Heidegger M. Sein und Zeit. 10. Aufl. Tübingen: Niemeyer; 1963.

59. Figueroa G. La bioética actual: las interrogantes de Heidegger. Rev Mé Chile 2011; 139: 1378-1383.

Recibido: 15 de mayo de 2021

Aceptado: 2 de junio de 2021 